\title{
Sustainable food systems: The global picture
}

W orldwide, public and private investments in agriculture and natural resources research benefitting our food systems have been enormously successful. These investments have fostered innovation and new technology, improved food security and human nutrition, developed new tools to maintain essential natural ecosystems, and generated economic benefits to producers, many signs point to the sobering reality that our current pace of innovation and gains in agricultural productivity will not be enough.

By 2050, the world population will top 9 billion people. Most of that growth will come in the world's developing countries. Improving dietary standards in rapidly developing economies like China and India have already increased demand for calories and protein, putting upward pressure on world cereal and oilseed prices while also increasing volatility in world markets. From a natural resources perspective, the United Nations estimates that in order to meet nutrition goals, world demand for water for irrigation will double by 2050, while demand for forest products is expected to increase $40 \%$ by 2060 . Perhaps most compelling, global food demands are expected to double by the middle of the century.

At the same time, our understanding of the expected impact of global climate change points to more stress on the global food system. Populations in the developing world, already vulnerable to food insecurity, will likely be the most seriously affected. The International Food Policy Research Institute (IFPRI) just published a study on the impact of climate change on global agriculture, which suggests that climate change will result in additional price increases for the world's most important agricultural crops: rice, wheat, corn and soybeans. Increasing crop prices will in turn put upward pressure on feed, aniprocessors and consumers alike. Looking ahead, however,

The Merriam-Webster dictionary defines sustainable as "of, relating to, or being a method of harvesting or using a resource so that the resource is not depleted or permanently damaged." For those of us engaged in agricultural research and extension, the term sustainability has often focused on farm-scale practices and solutions and regional food-system issues. The rapidly emerging international view is that sustainability must be considered in a global context, especially as it relates to food production, environmental and social protection, and climate change.

Moreover, there is increasing awareness that intensive agriculture must and will play new roles in sustainable food systems, and that productivity gains from research, innovation, new technologies and education are essential. Feeding the world amid a changing climate forces us to critically review our traditional models and to realign our thinking with new priorities.

We must recognize that enhancing food security and adapting to climate change go hand-in-hand.

We must develop agricultural sustainability programs and policies that contribute to food security and climate change adaptation.

We must develop technologies to sustainably produce more with less.

Investment in research, development and delivery is a moral imperative.

We already know that meeting local

\section{Feeding the world amid a changing climate forces us to critically review our traditional models and to realign our thinking with new priorities.}

mal products and meat. Higher temperatures, especially in agriculturally important areas of the developing world, will reduce the yields of desirable crops, while changes in the amount and timing of precipitation will increase the likelihood of short-term crop failures and long-term production declines.

The message is clear. The historic challenges to produce safe and abundant food and fiber, to address poverty while safeguarding the environment and guiding sustainable energy development, and meanwhile to stimulate economic growth and jobs, must all now be assessed in the context of climate change and the need for sustainable development at the global level. and global food demand will require diverse production systems, and that those systems must make key adaptations based on understanding the biology of climate change, new pests and diseases, and crop adaptations. We also know that the challenges for public policy, resource management and science agencies are growing exponentially and intersect as never before.

For all segments of the University of California's Division of Agriculture and Natural Resources, these challenges offer both exciting opportunities to foster innovation through research and outreach, and great responsibility to align our priorities with those issues where we have the greatest potential to make the biggest difference.

Find links to resources for this editorial at: http://ucanr.org/repository/CAO/issue.cfm?issue $=$ current 